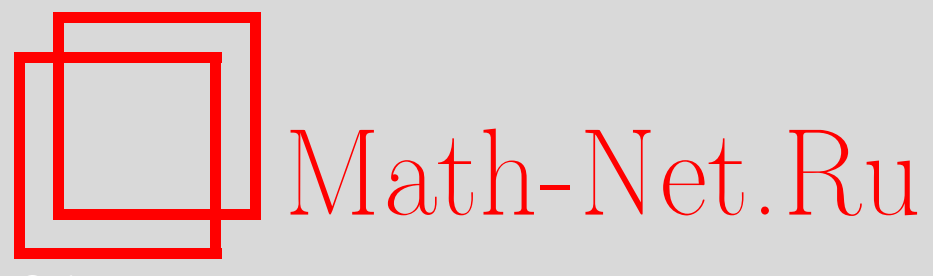

Л. Белопухов, Календарь и астрономия, Квант, 2020, номер 2, 2-8

DOI: https://doi.org/10.4213/kvant20200201

Использование Общероссийского математического портала Math-Net.Ru подразумевает, что вы прочитали и согласны с пользовательским соглашением http://www.mathnet.ru/rus/agreement

Параметры загрузки:

IP : 18.208 .226 .222

26 апреля 2023 г., 15:40:05

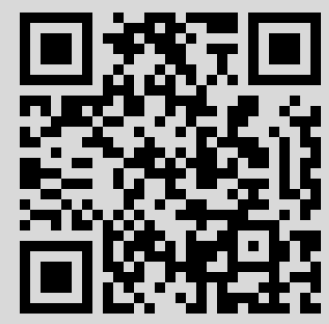




\section{Календарь и астрономия}

\section{Л.БЕЛОПУХОВ}

$\mathrm{B}$ ТЕЧЕНИЕ БОЛЕЕ ШЕСТИДЕСЯТИЛЕТ судьбоносное для России событие отмечалось каждый год 7 ноября, хотя само событие носит имя не ноябрьской, а октябрьской революции. Всем известно формальное объяснение этого расхождения разница в 13 дней между «старым» и «новым» стилями, точнее между юлианским и григорианским календарями.

Любители истории знают, что юлианский календарь назван так в честь древнеримского государственного и политического деятеля, диктатора и великого понтифика (жреца) Юлия Цезаря, а григорианский - в честь Папы Римского Григория XIII. Но на вопрос, а зачем в 1582 году понадобилось изменить календарь, применявшийся свыше полутора тысяч лет, редко можно получить вразумительный ответ. Автор (преподаватель физики в инженерном вузе) неоднократно задавал этот вопрос студентам при знакомстве с азами кинематики вращательного движения. За последние 10 лет более или менее приемлемый ответ могли дать в среднем один-два студента из ста.

DOI: https://doi.org/10.4213/kvant20200201

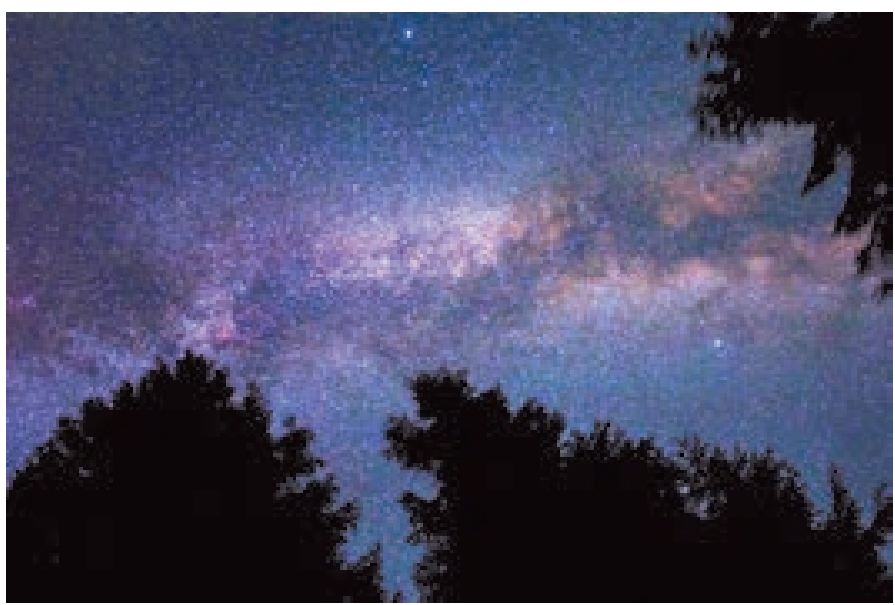

Причина ясна - исключение около 20 лет назад из школьного образования курса астрономии и замена его элементарными астрономическими сведениями в младших классах в предмете «Окружающий мир» . Сейчас положение как будто начинает исправляться - вот уже третий год в одиннадцатом классе один урок физики заменен астрономией. Но это - капля в море.

Данная статья - попытка заинтересовать астрономией читателей «Кванта», попытка, основанная на знакомстве с проблемой календаря.

\section{Необходимость календаря}

Календарь необходим для фиксации периодических изменений в окружающем мире. «Чувство календаря» всегда было присуще человеку, да и всему живому в природе. Прежде всего, это связано с чередованием времен года как перехода погоды от более холодной к более теплой и обратно. Оформление этого чувства в определенные понятия и слова было, повидимому, связано с переходом человечества от собирательства и охоты, как средств добычи пищи, к земледелию и скотоводству. Необходимые для этого укрупнения племен и переход к оседлой жизни привели к бурному развитию языкового общения.

В речи появились названия для обозначения времен года и других периодических явлений в природе. Самым коротким периодом были, конечно, сутки - смена дня и ночи. А самым длинным был год - период полного цикла смены времен года. Оба эти цикла связаны с Солнцем, как источником тепла и света, поэтому оно у всех племен стало богом, без которого жизнь была бы невозможна. 
Но для промежуточных циклов - самих времен года (по-нашему - кварталов) и их долей (месяцев) природа дала еще один цикл - смену фаз Луны. Сегодня мы их называем новолунием, первой четвертью, полнолунием и последней четвертью. В фазах-четвертях мы видим половину лунного диска, освещенного Солнцем. В неполных фазах Луна нам видится в виде криволинейного кругового сегмента, похожего не серп.

У многих народов для периода полной смены лунных фаз появилось слово «месяц», которое заодно означало и название самой Луны. Месяц для календаря стал удобнее, чем квартал (время года). Например, в весне можно выделить время дождей, время сева и время первой прополки, а в летнем периоде - время сенокоса, время жатвы и время созревания фруктов. Месяц удобно разделить на четыре части (совпадающие с лунными фазами), в каждой из которых по 7 суток. Вот где таится привычный нам счет дней по неделям! Такой стихийный недельно-лунный календарь принято называть просто лунным.

Но когда возникло умение считать до сотни, а потом и до тысячи, этот грубый календарь стал уточняться. Прежде всего это относилось к соотношению длительностей года и месяцев. Среди людей стали выделяться те, кто вел счет дням, месяцам и годам. Еще двести лет назад на земле уже можно было найти народы, у которых календарь велся по зарубкам на дереве или по насечкам на мягком камне (точь в точь, как это делал Робинзон на своем необитаемом острове). Возможно, что именно такие люди были жрецами и наряду со счетом времени организовывали всю духовную жизнь, предсказывали события, создавали традиции и обычаи и руководили всей хозяйственной деятельностью своего племени.

\section{Древние астрономические достижения}

Жрецы первыми обратили внимание на неточность отношения солнечного и лунного периодов. Казалось бы, по простому счету, в году должно было быть ровно 12 лунных месяцев - 4 сезона по 3 месяца

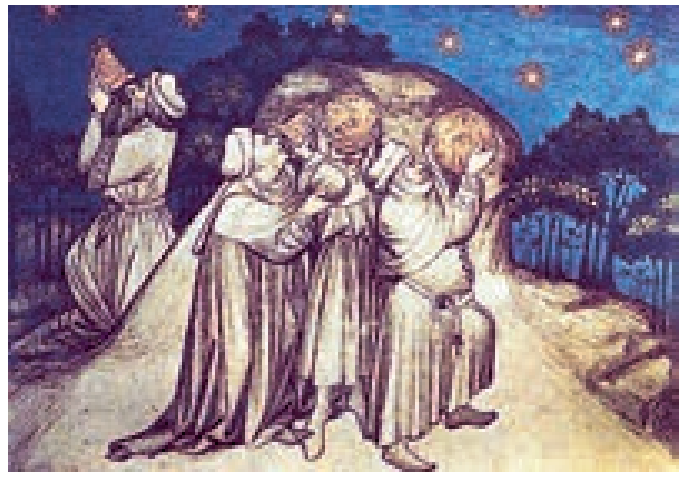

каждый. Но оказалось, что это число очень приблизительно. Лунных месяцев в году не 12 , а на одну треть месяца больше -

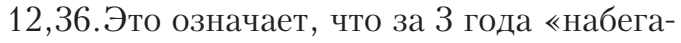
ет» целый лунный месяц, а за 9 лет будет происходить сдвиг календаря на целый сезон. С этим надо было что-то делать.

Прежде всего жрецы монополизировали календарный подсчет дней и завели обычай объявлять народу о наступлении того или иного сезона и начале очередных сельскохозяйственных и иных работ. Но «для себя» им необходимо было разобраться с этим вопросом и создать правильный календарь, сохраняя его в тайне.

Выяснилось, что и отношение периода лунного цикла смены фаз к суткам является не целым числом, а равно примерно 29,5 , следовательно, и длительность каждой фазы не составляет ровно 7 суток.

Вот эти нецелые отношения природных периодических процессов и есть главная причина того, что на нашей планете действовало не меньше десятка разных календарей, в которых главной задачей было согласование 12 лунных месяцев с годичным солнечным циклом. Такие календари получили название лунно-солнечных и солнечных. Но для них нужно было достаточно точно знать солнечный и лунный периоды в сутках.

Прежде всего следовало определиться с моментом начала отсчета годичного солнечного периода. Ведь никакой «службы времени» не существовало. И не было другого пути, кроме выбора определенного положения Солнца на небе, например наивысшего положения Солнца во время 
самого длинного дня (летнего солнцестояния). А как фиксировать положение Солнца на небе? Сегодня это не представляет труда. Подобно тому как на поверхности Земли в качестве координат используются два угла на сферической поверхности (широта и долгота), на внутренней поверхности сферы звездного неба тоже можно применять угловые сферические координаты. Для этого существуют специальные измерительные приборы. Но такие приборы еще только предстояло создать - самые древние из них были изобретены в Вавилоне и Древней Греции в пятом-четвертом веках до нашей эры. А календари уже существовали.

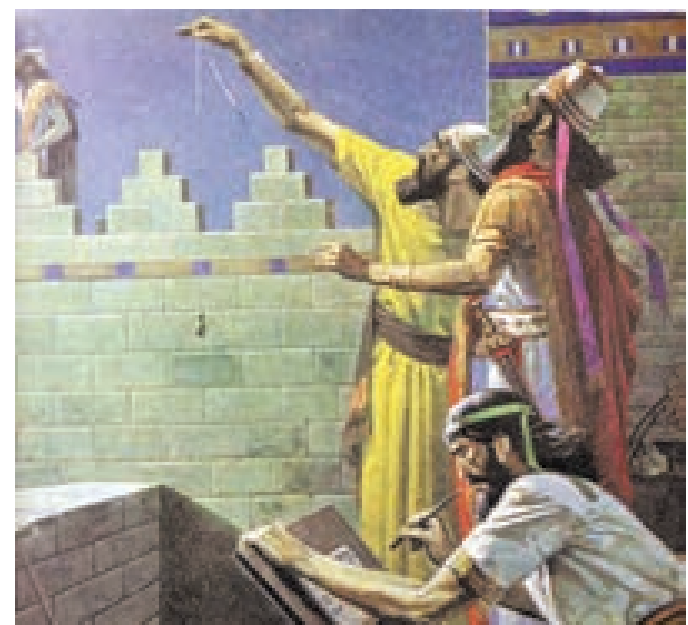

Аналогом угловых координат у древних звездочетов стали созвездия. Еще в глубокой древности было замечено, что ночное небо можно условно разделить на участки, в каждом из которых расположена группа звезд, образующая схематический рисунок. Этим группам (созвездиям) стали присваивать различные названия, большая часть которых была именами богов и мифологических героев, а также животных. Названия созвездий и были первыми координатами на небесной сфере. Древние греки различали 88 таких «координат».

На протяжении жизни нескольких поколений звездный рисунок выглядел неизменным - звезды казались как бы прикрепленными к небесной сфере, которая как целое вращалась вокруг земного наблюдателя, описывая полный круг за сут- ки. Если набраться терпения и безлунной ночью неподвижно сидеть, глядя на небо, то нетрудно определить, что за пару часов небесная сфера со звездами поворачивается на угол примерно $30^{\circ}$. Эту завораживающую панораму чудесно выразил наш великий поэт:

Морозна ночь, все небо ясно,

Светил небесных дивный хор

Течет так тихо, так согласно.

Конечно, мы знаем, что на самом деле «дивный хор» никуда не течет. Не звездная сфера вращается вокруг неподвижной Земли, а, наоборот, Земля вращается вокруг своей оси. Но тысячи лет почти все люди, глядя на небо, думали по-другому. Инакомыслящих были единицы, их заставляли молчать. Первым, кто выдвинул гелиоцентрическую систему мира и сделал ее обоснование, был выдающийся греческий математик, астроном и философ Аристарх Самосский (третий век до нашей эры). Но на него обрушились проклятия жрецов. Понадобилось почти две тысячи лет, чтобы трудами Коперника, Кеплера, Галилея и многих других астрономов геоцентрическая система уступила гелиоцентрической. Да и то не сразу. Знаменитое «а все-таки она вертится!» великий Галилей скорее всего произнес мысленно, покидая суд инквизиции с обещанием вслух так больше не говорить.

Вот почему изначально все календари исходили из геоцентрической системы мира, в которой Земля неподвижна. Да и сегодня она хороша не только как поэтический образ. Геоцентрическая система удобна для создания календарей. Именно на ней построена сферическая астрономия, которая вводит некую воображаемую сферу на огромном расстоянии от Земли, много большем, чем расстояние от Земли до Солнца. Действительно, даже ближайшая к Солнцу звезда находится от нас на расстоянии в 270000 раз большем.

\section{Движение Солнца в геоцентрической системе}

Движение Солнца по небесной сфере в геоцентрической системе имеет непростой 
характер. Наблюдаются два периодических цикла движения и изменения угловых координат. Один цикл - суточный, в котором можно фиксировать максимальную высоту поднятия Солнца над горизонтом (или минимальную длину тени от вертикального столба). А другой цикл - годичный, в котором эта максимальная высота (кульминационное положение Солнца) в течение года перемещается от некоторого минимума до максимума и обратно. Если, например, на широте Москвы 22 декабря кульминация Солнца составляет угол $16,5^{\circ}$ с плоскостью небесного экватора, то 21 марта и 22 сентября этот угол равен $40^{\circ}$, а 22 июня - 63, $5^{\circ}$.

Окружность, проведенная на небесной сфере через эти точки, носит название «эклиптики» (от древнегреческого

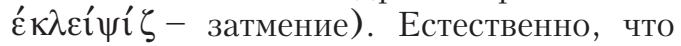
время полного перемещения Солнца по эклиптике составляет год, а месячное угловое перемещение равно $30^{\circ}$. Оказывается, что перпендикулярная кругу эклиптики ее ось не совпадает с осью вращения Земли или, что то же самое, ось вращения Земли не перпендикулярна плоскости ее солнечной орбиты, а составляет с ней угол $23,5^{\circ}$. Этот угол и является причиной смены времен года. Простое следствие - на широте $23,5^{\circ}$ в высшей кульминационной точке (в полдень 22 июня) Солнце находится прямо над головой. Напомним, что этот факт во втором веке до нашей эры был использован математиком и астрономом античности Эратосфеном для определения размера Земли.

Из наклона земной оси вытекает еще один факт. В моменты максимальной солнечной кульминации на Земле - самый длинный день, а в моменты минимальной кульминации - самый короткий. Совершенно очевидно, что существуют такие промежуточные кульминации, для которых время дня равно времени ночи. Соответствующие дни весной - 20(21) марта, осенью - 22(23) сентября. Эти дни получили название дней равноденствия (точнее было бы слово «равноночеденствие»).

А дни максимальной и минимальной кульминации назвали днями солнцестоя- ния (летнего и зимнего). Почему они так называются? Дело в том, что скорость изменения склонения Солнца (или, другими словами, угловая скорость воображаемой линии от Земли к Солнцу) в дни равноденствий значительно больше, чем в дни солнцестояний. За 5 суток до или после равноденствия максимальное склонение Солнца изменяется на 4 градуса, что хорошо заметно на небе. А за те же 5 суток от момента солнцестояния склонение изменяется всего лишь на 2 угловые минуты. Это и создает впечатление некоторого «стояния» Солнца летом и зимой в моменты его кульминации. Убедиться в этом легко, обратив внимание на то, что длительность светового дня с точностью до одной минуты одна и та же в течение нескольких дней в районе летнего солнцестояния, а во время равноденствий день равен ночи (с точностью до минуты) не больше двух суток.

\section{Возникновение астрологии}

Уже отмечалось, что «координатами» положения Солнца на небесной сфере в моменты его максимального подъема в древности служили созвездия. И оказалось, что на каждый месячный сдвиг положения Солнца на эклиптике $\left(30^{\circ}\right)$ приходится одно созвездие. Из 12 этих созвездий 7 имели названия животных (Овен, Телец, Рак, Лев, Скорпион, Козерог и Рыбы). Поэтому вся эклиптика получила

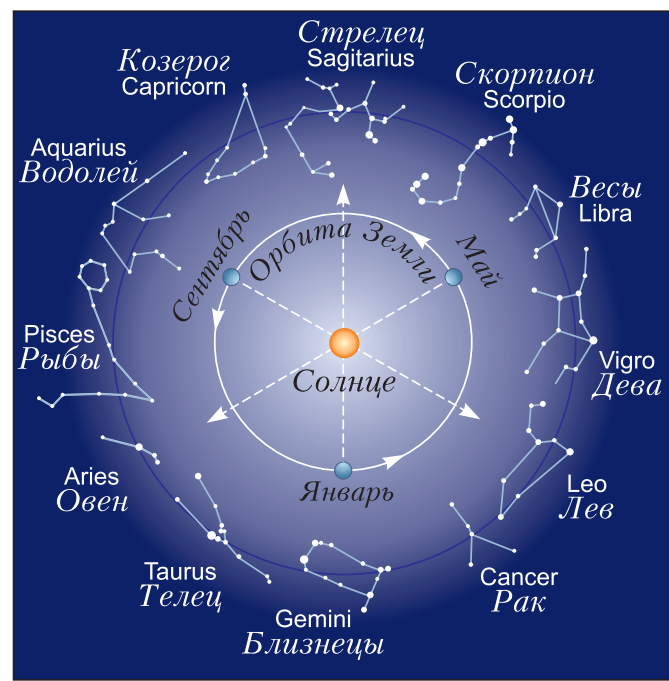


в античной древности название круга 3о-

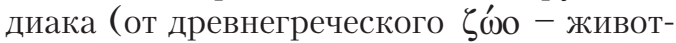
ное), а каждое из 12 созвездий стало знаком Зодиака.

Еще в глубокой древности «наблюдатели неба» заметили, что на ночном небе некоторые объекты ведут себя не так, как все многочисленные остальные светила, остающиеся на своих местах. Эти объекты перемещались, месяц от месяца попадая в разные созвездия, причем перемещения эти были очень непростыми, иногда даже с возвратным движением. Все они получили имена богов, мы знаем их в латинском звучании - Меркурий, Венера, Марс, Юпитер и Сатурн. В божественности Луны и Солнца, тоже перемещавшихся по небу, с древнейших времен сомнений не было. Все эти 7 перемещающихся объектов греки так и назвали «блуждающими» $(\pi \lambda \alpha \nu \eta \tau \eta \zeta$ по-гречески).

Факт перемещения Солнца по кругу 3одиака в сочетании с изменяющимся положением планет на звездной сфере легли в основу астрологии ( от греческих $\alpha \zeta \tau \rho о \nu-$ звезда и $\lambda \omega^{\prime} \gamma \zeta$ - мысль, слово). Астрологи постулировали, что на судьбу людей, начиная с момента рождения, влияют положения Солнца и планет на небесной сфере. А эти положения можно предсказывать. Появились астрологические прогнозы.

Может возникнуть вопрос: как же древние астрологи определяли зодиакальные созвездия, в которых находилось Солнце в момент его суточной кульминации? Ведь днем звезд не видно, особенно вблизи Солнца. Но оказывается, что днем со дна глубокого и узкого колодца прекрасно видны звезды и созвездия. Нужно только было иметь такие колодцы, прорытые под разными углами к земной поверхности. А когда были изобретены первые угловые измерительные инструменты, колодцы стали ненужными. Ночью можно было определить то созвездие, которое находилось на небе под углом, измеренным днем для положения Солнца в момент его наивысшего подъема.

Сначала эти измерения проводились во время летнего солнцестояния (максимальный угол подъема Солнца и минимальная

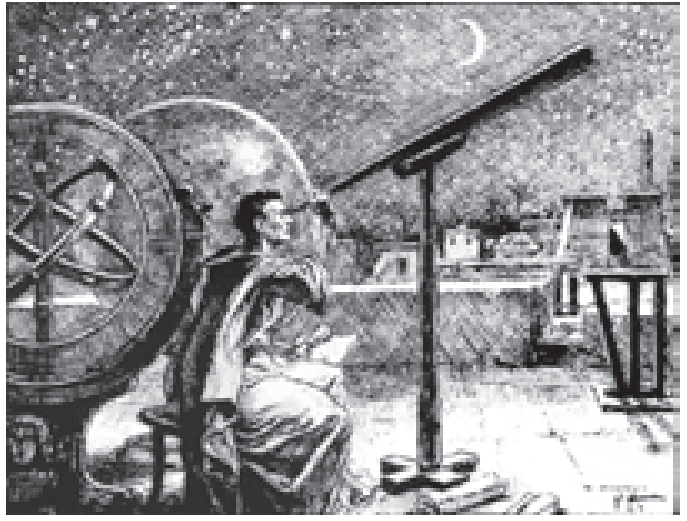

скорость его перемещения по эклиптике), что и определяло начальное положение Солнца на зодиакальном круге. Но усовершенствование измерительных инструментов греческими астрологами (их в Греции стали чаще называть астрономами) позволило проводить точные измерения и в дни весеннего равноденствия. Это произошло свыше 2000 лет назад, когда Солнце наблюдалось в созвездии Овена, и было сделано во втором веке до нашей эры греческим астрономом, математиком и механиком Гиппархом. И именно тогда был создан тот астрологический канон, которым пользуются и современные астрологи.

Но затем Гиппарх на основе своих точных измерений пришел к неожиданному выводу, что на небесной сфере точка кульминации Солнца в день весеннего равноденствия медленно перемещается вдоль эклиптики. Скорость этого перемещения невелика. На один градус дуги эта точка перемещается за 72 года. Но за 1000 лет астрологических измерений до Гиппарха перемещение составило уже 14 градусов. А за 26000 лет оно составит на небесной сфере уже полный круг в $360^{\circ}$. Гиппарх назвал это явление предварением равноденствий (позднее появилось латинское слово precessia, в буквальном переводе предшествование).

\section{Ошибки астрологов и их гороскопов}

Открытие Гиппархом предварения равноденствий означает, что даты равноденствий и, соответственно, положение Солн- 
ца на эклиптике относительно созвездий тоже должны изменяться - примерно на одно созвездие за 2000 лет. При этом должна меняться и длительность пребывания Солнца на «участке» того или иного созвездия. Во время Гиппарха эта длительность колебалась в пределах 28-30 дней, что и зафиксировано в астрологическом каноне, которым пользуются до сих пор. Но в наше время это совершенно другая длительность, она сейчас колеблется в пределах от 8 до 44 дней.

Мало того, на современной картине звездного неба солнечная эклиптика пересекает уже не 12, а 13 созвездий. В число знаков Зодиака теперь входит и созвездие Змееносца (с 30 ноября по 18 декабря). И даты рождения современных людей соответствуют совсем другим (соседним) знакам Зодиака.

Из этих неопровержимых астрономических данных следует, что все астрологические прогнозы (гороскопы) о судьбах людей, определяемые по старинному, двухтысячелетней давности, канону, сейчас бессмысленны, а если и бывают совпадения, то они чисто вероятностные. Но ведь известно, что выдающиеся астрономы эпохи Возрождения и Нового времени тоже составляли астрологические прогнозы. И это было для них единственным источником средств для жизни, а главное, для приобретения необходимых приборов и инструментов. Властные и богатые люди щедро платили за гороскопы, особенно если они сбывались. Например, предшественнику Кеплера датскому астроному Тихо Браге король Дании Фридрих II подарил целый остров и построил для него замок Ураниенбург, оснащенный самыми

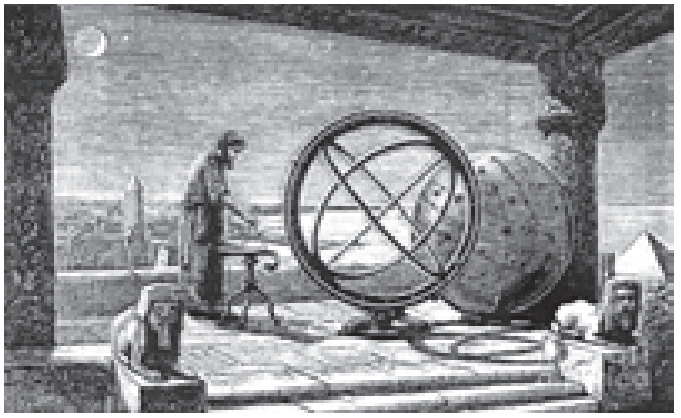

лучшими приборами для изучения неба (Урания - муза астрономии). Иоганну Кеплеру приписывают такие слова: «Астрология - дочь астрономии. Естественно, что дочь должна кормить мать, которая без нее умерла бы с голоду». Но множество астрологов ничего не сделали полезного в астрономии, а попросту занимались прибыльным делом.

\section{Причина предварения равноденствий}

Гиппарх догадывался, что открытое им явление предварения равноденствий связано с вращением Земли вокруг своей оси, в чем он был уверен, как и его предшественник Аристарх Самосский. Какова же связь вращения Земли с этим явлением, которое в римское время стали называть прецессией?

Заметим, что XVIII веке ученые назвали этим словом другое явление, характеризующее вращение массивных тел, имеющих в данной системе отсчета одну неподвижную точку, - гироскопов (волчков). Это явление знакомо каждому с детства. При наклоне игрушечного волчка (юлы) ось вращения начинает описывать коническую поверхность. Это придает устойчивость положению волчка, потому что среднее положение вектора оси остается вертикальным. Вращательное движение оси волчка есть следствие закона динамики вращательного движения твердого тела. На обычный волчок действует момент силы тяжести, приложенной к центру масс волчка. Вектор этого момента все время остается перпендикулярным оси вращения, что и вызывает поворот этой оси. А постоянный поворот оси и означает ее вращение (прецессию). Угловая скорость прецессии всегда значительно меньше угловой скорости самого волчка.

Астрономы применили законы прецессии гироскопа к вращающейся Земле. Для земного шара вращающим моментом может быть только суммарный момент сил тяготения между Землей и массивными телами солнечной системы - самим Солнцем, Луной и планетами Солнечной системы. Если бы Земля имела форму идеального однородного шара, то момент этих 
сил был бы равен нулю, потому что все эти силы можно было бы считать приложенными к ее центру. Но Земля не шар и не абсолютно твердое идеально однородное тело. Вращение Земли приводит к сплюснутости у полюсов, ее экваториальный радиус на 20 километров больше полярного. Эта причина и неоднородность земного вещества приводят к неравенству нулю суммарного момента сил тяготения со стороны объектов Солнечной системы. Он и вызывает прецессию земной оси. Так называемые «полюсы мира», проекции земной оси на небесную сферу, перемещаются по ней, описывая окружности с угловым раствором дважды по 23, $5^{\circ}$. В гелиоцентрической системе, где неподвижно Солнце, это соответствует углу между осью вращения Земли и плоскостью земной орбиты. Выше уже отмечалось, что это и есть причина смены времен года.

Ось вращения медленно, но верно поворачивается, угловая скорость этого поворота соответствует периоду вращения 26000 лет. И времена года должны так же медленно перемещаться по годичному календарю - примерно на месяц за каждые 2200 лет. И соответственно этому для каждой местности на Земле (ее географической широты) будет меняться кульминационная суточная высота Солнца над горизонтом и среднегодичное значение этой высоты, т.е. будет меняться климат. Возможно, что это и есть причина периодического появления и исчезновения так называемых малых ледниковых периодов в умеренных широтах (другая возможная причина - долгопериодные изменения солнечной активности).

Совершенно очевидно, что прецессия земной оси должна находить какое-то отражение в календарных системах, прежде всего в таких, которые связаны со звездным небом, например в астрологическом календаре. В других календарях она вно- сит небольшую поправку и никогда не учитывалась вплоть до современного, григорианского календаря. В этом календаре используется так называемый истинный или тропический год, длительность которого определяется как промежуток времени между двумя последовательными прохождениями центра диска Солнца через точку весеннего равноденствия. Тем самым, влияние прецессии земной оси при этом уже учтено автоматически. И проблемой разработки солнечных календарей становится согласование длительности тропического года с длительностью суток. Длительность тропического года в современную эпоху составляет 365, 2422 суток. И эта «добавка» 0,2422 должна быть близкой к некоторому рациональному числу отношению целых чисел.

В статье В.Г.Сурдина «Високосное летосчисление» в сборнике «Математическая составляющая» (М.: Фонд «Математические этюды») рассматривается общий принцип построения календарей на основе математического аппарата под названием «цепные дроби». Вычисленные с помощью этого аппарата рациональные добавки составляют (в сутках) 1/4, 7/29, 8/33, $31 / 128 \ldots$ Это означает, что к 365 суткам в календарном году должны добавляться 1 сутки раз в 4 года, 7 суток - раз в 29 лет, 8 суток - раз в 33 года, 31 сутки - раз в 128 лет и т.д. Среднегодовая погрешность при этом будет все меньше и меньше - 11,25 минуты для дроби 1/4, 70 секунд для дроби 7/29, 20 секунд для дроби 8/33 и чуть меньше 1 секунды для дроби 31/128.

Читатель уже сразу замечает, что вариант с $1 / 4$ - это и есть юлианский календарь с его «високосной» добавкой 29 февраля 1 раз в 4 года. А что же такое нынешний григорианский календарь с этой математической (арифметической) точки зрения? Ответ на этот вопрос - во второй части статьи.

(Продолжение следует) 